\title{
Laceração peniana em cavalo Mangalarga Marchador
}

\author{
Penile laceration in a Mangalarga Marchador stallion
}

\author{
Carla Fredrichsen Moya-Araujo (D) ${ }^{1 *}$, Adriano Felipe Mendes (D) ${ }^{1}$, Mariana Marcantonio Coneglian (iD ${ }^{1}$, \\ Annelise Carla Camplesi (D) ${ }^{2}$, Gustavo Henrique Marques Araujo (iD ${ }^{3}$ \\ ${ }^{1}$ Departamento de Medicina Veterinária, Universidade Estadual do Centro-Oeste (UNICENTRO), Guarapuava, PR, Brasil \\ 2 Departamento de Clínica e Cirurgia Veterinária, Universidade Estadual Paulista (UNESP), Jaboticabal, SP, Brasil \\ ${ }^{3}$ Curso de Medicina Veterinária, Universidade Federal de Goiás (UFG), Jataí, GO, Brasil
}

\section{Resumo}

Foi atendido na Clínica Escola de Medicina Veterinária da Unicentro um garanhão Mangalarga Marchador de 4 anos de idade, com queixa de lesão em pênis. 0 proprietário relatou que o animal havia ferido o pênis em cerca de arame liso havia duas semanas. 0 paciente foi medicado na propriedade com benzilpenicilina associada à estreptomicina, além de terapia anti-inflamatória à base de dexametasona, durante três dias consecutivos, sem melhora clínica. Ao exame físico, observou-se dor intensa e edema em prepúcio que dificultava a exposição do pênis. Foi necessária a administração de acepromazina para a avaliação do órgão. A laceração se estendia da porção dorsal até a ventral do terço médio do corpo do pênis, sem comprometimento do prepúcio, sendo recoberta por áreas de necrose e apresentando odor fétido e sangramento. Não foram detectadas demais alterações clínicas. Foi realizado hemograma, não sendo observadas alterações nos parâmetros hematológicos. 0 animal permaneceu internado e o tratamento preconizado foi administração de flunixin meglumine $(1,1 \mathrm{mg} / \mathrm{kg}$, IV a cada 24 horas) e omeprazol ( $2 \mathrm{mg} / \mathrm{kg}$, VO a cada 24 horas) durante cinco dias consecutivos, associados a curativo local, o qual era precedido por ducha fria em prepúcio, seguida de massagem com dimetil sulfóxido (DMSO) gel; ao redor da lesão era aplicado spray repelente. 0 pênis foi exposto para a limpeza da ferida com gaze embebida em solução de $\mathrm{NaCl}$ 0,9\%, seguida pela aplicação de pomada à base de clorexidina $(0,7 \mathrm{~g} / 100 \mathrm{~mL})$, procedimento este realizado a cada 12 horas, durante 45 dias. No segundo dia de tratamento foi possível observar a diminuição do edema e após cinco dias o animal já expunha o pênis para urinar, com completa cicatrização ao final do tratamento, após 45 dias, quando recebeu alta hospitalar. Na estação de monta seguinte, o animal retornou às atividades reprodutivas sem apresentar alterações anatomofisiológicas.

Palavras-chave: Lesão peniana. Tratamento clínico. Equino. 


\section{Abstract}

A four-year-old Mangalarga Marchador stallion was treated with a complaint of penile injury at the Clinic School of Veterinary Medicine Unicentro. The owner reported that the animal had injured the penis in smooth wire for two weeks. The horse was treated with benzilpenicillin associated with streptomycin, in addition to anti-inflammatory therapy based on dexamethasone, during three consecutive days, without observing clinical improvement. Physical examination showed intense pain and foreskin edema that made it difficult to expose the penis. Administration of acepromazine $(0.05 \mathrm{mg} / \mathrm{kg}, \mathrm{IV})$ was required for organ evaluation. The laceration extended from the dorsal to ventral portion of the middle third of the penis body without involvement of the prepuce, being covered by areas of necrosis, foul smell and bleeding. No other clinical changes were detected. There were no changes on the haematological parameters. The horse was hospitalized, and the recommended treatment was administration of flunixin meglumine $(1.1 \mathrm{mg} / \mathrm{kg}, \mathrm{IV}$, every 24 hours) and omeprazole ( $2 \mathrm{mg} / \mathrm{kg}, \mathrm{VO}$, every 24 hours) for five consecutive days, associated with local dressing. This was preceded by cold shower in the foreskin, followed by massage with DMSO gel and repellent spray around the lesion. The penis was exposed for wound cleaning with gauze soaked in $0.9 \% \mathrm{NaCl}$ solution followed by application of chlorhexidine $(0.7 \mathrm{~g} / 100 \mathrm{~mL})$ ointment, a procedure performed every 12 hours for 45 days. On the second day of treatment the edema was decreased, and after five days the horse already exposed the penis to urinate, with complete healing at the end of the treatment. The horse returned to the reproductive activities on the following breeding season, performing mating without presenting anatomical and physiological alterations.

Keywords: Penile lesion. Clinical treatment. Equine.

\section{Introdução}

O pênis pode ser lesionado quando o cavalo falha em saltar sobre um obstáculo, durante a cópula, pela presença de fios da cauda da fêmea e coices, ou pelo contato com couro ressecado do manequim estático durante a colheita de sêmen (Taylor, 1980; Schumacher e Varner, 2011). A maioria das lacerações atinge apenas o tegumento, mas pode se estender para o corpo cavernoso até a uretra peniana (Perkins et al., 2003). Quando há comprometimento do corpo cavernoso, há presença de intensa hemorragia, principalmente durante a ereção e no final da miccção. Nos casos acompanhados de lesão da uretra peniana, uma área de necrose é formada ao redor da lesão, com extravasamento de urina pela ferida (Perkins et al., 2003; Schumacher e Varner, 2011).

O diagnóstico de laceração peniana baseia-se no histórico e no exame físico específico da gentitália externa. Normalmente, a inspeção e palpação devem ser realizadas com o pênis em ereção, o que ocorre durante a cópula ou colheita de sêmen em vagina artificial (Borges et al., 2017). Em animais que são mais agressivos ou com dor intensa, fazse necessária a sedação para a avaliação clínica do sistema reprodutor equino. Nesses casos, os fármacos comumente utilizados para que a avaliação seja possível com o animal em posição quadrupedal são os fenotiazínicos e os alfas-2-agonistas. A acepromazina é um fenotiazínico amplamente utilizado em medicina veterinária, cujos efeitos são observados em até 30 minutos após a aplicação, e que está associado ao priapismo, o que nestas situações é desejado (Franco et al., 2017).

0 ideal é que a avaliação e o reparo ocorram o mais rápido possível, a fim de restaurar a função estética e anatômica, além de controlar uma possível infecção. Os melhores resultados se dão dentro das primeiras seis horas, permitindo o tratamento por primeira intenção através de sutura com fio absorvível. Quando a laceração ocorreu há mais de 24 horas, esta pode evoluir para um quadro infeccioso, resultando em edema inflamatório, o qual, quando intenso, pode impedir a retração peniana ou a exposição do mesmo. Nestes casos, muitas vezes a única opção é o tratamento médico com intuito de reduzir a infecção e a inflamação, e permitir a cicatrização através da limpeza da ferida com debridamento das áreas de necrose.

Dependendo da gravidade do processo infeccioso, indica-se proceder à limpeza da ferida e fazer uso, várias vezes ao dia, de pomada contendo antimicrobiano até que haja melhora clínica. A administração de anti-inflamatório não esteróide é indicada para redução do edema prepucial. Se houver 
o comprometimento de outros segmentos penianos, a correção cirúrgica específica deve ser realizada (Schumacher e Varner, 2011; Auer e Stick, 2012).

Frente ao exposto, o presente trabalho tem por objetivo descrever um caso de laceração peniana em garanhão, uma vez que as afecções do genital masculino afetam diretamente a eficiência reprodutiva do animal e podem trazer importantes perdas econômicas ao proprietário.

\section{Relato de caso}

Foi atendido na Clínica Escola de Medicina Veterinária da Unicentro (Cevet) um garanhão, 4 anos de idade, da raça Mangalarga Machador, com histórico de lesão em pênis. 0 proprietário relatou que o animal feriu o pênis em cerca de arame liso havia duas semanas, sendo medicado na propriedade, durante três dias consecutivos, com benzilpenicilina associada à estreptomicina, além de terapia anti-inflamatória à base de dexametasona, mas sem apresentar melhora clínica. A causa da laceração é condizente com os relatos literários, que indicam a falha em saltar sobre um obstáculo como uma das etiologias da enfermidade (Taylor, 1980; Silva et al., 2010; Schumacher e Varner, 2011), já que nesse caso o garanhão havia tentado saltar uma cerca de arame liso enquanto o pênis encontravase exposto. 0 animal era mantido em pastagem com duas fêmeas saudáveis, estava vacinado contra tétano, influenza e encefalite viral, recebia ração e suplemento mineral no cocho e água ad libitum oriunda de represa.

Não foram observadas alterações no exame físico geral. Contudo, no exame físico específico do genital externo, durante a inspeção e palpação foi possível notar presença de edema e dor intensa em prepúcio, dificultando a exposição do pênis para a avaliação. Quando o tratamento realizado não é adequado, o quadro evolui para processo infeccioso com intenso edema inflamatório (Schumacher e Varner, 2011), por isso se fez necessária a administração de acepromazina $(0,05 \mathrm{mg} / \mathrm{kg}$, IV) para exame do órgão, uma vez que esse fármaco está associado a priapismo em equinos (Franco et al., 2017).

Após a exposição peniana, observou-se que a laceração se estendia da porção dorsal até a ventral do terço médio do corpo do pênis, envolvendo apenas o tegumento, sem comprometimento do corpo cavernoso ou da uretra peniana, estando recoberta por áreas de granulação e necrose e apresentando odor fétido e a presença de pouco sangramento (Figura 1A); não houve, entretanto, comprometimento do prepúcio. Uma das possíveis complicações relatadas na literatura em casos de laceração peniana é a presença de hemorragia intensa, principalmente quando há envolvimento do corpo cavernoso (Perkins et al., 2003; Schumacher e Varner, 2011), o que não foi observado neste caso, já que apenas o tegumento foi atingido.

Foi realizada colheita de sangue por meio de venopunção jugular para avaliação hematológica e não foram observadas alterações, sugerindo que o quadro infeccioso estava restrito ao local da lesão.

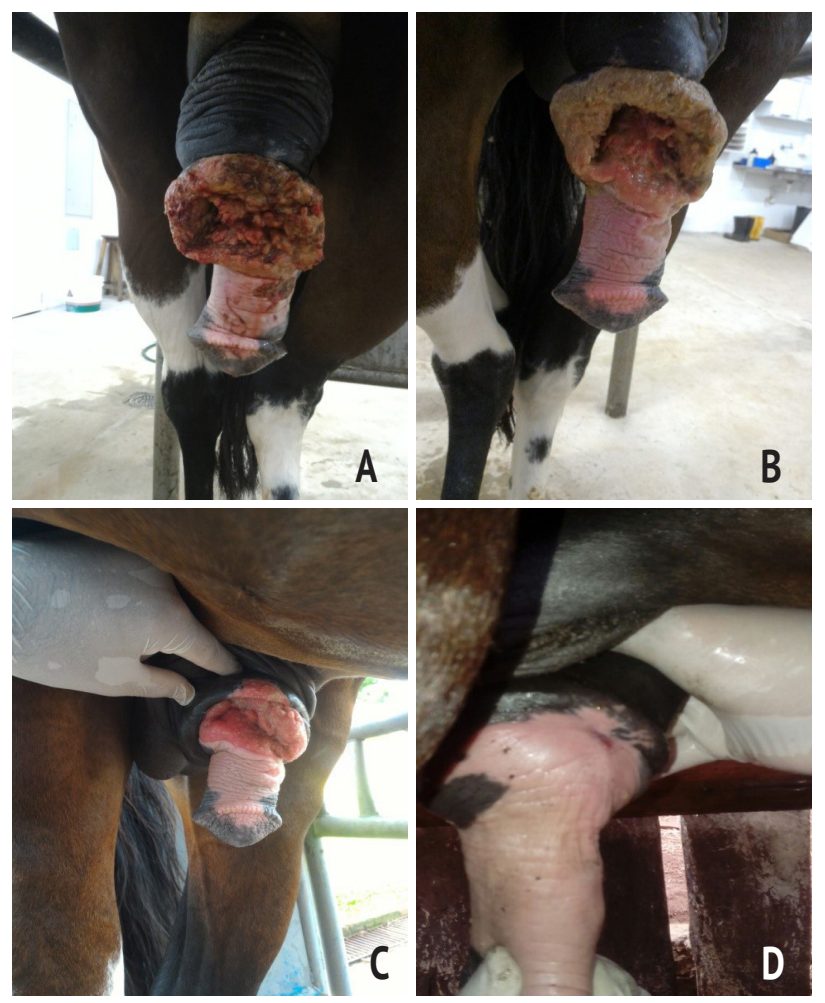

Figura 1 - Imagem da (A) lesão no pênis de garanhão Mangalarga Marchador no dia do atendimento, apresentando intensa granulação e tecido necrosado. (B) Ferida após cinco dias de tratamento. (C) Aspecto da lesão após dez dias de tratamento, com marcada redução do tecido de granulação e aproximação das bordas da ferida. (D) Pênis do garanhão no dia da alta hospitalar, com completa cicatrização da lesão. 
Com a lesão tendo ocorrido há duas semanas e o quadro infeccioso instaurado, optou-se por tratamento clínico, uma vez que a correção cirúrgica é indicada normalmente dentro das primeiras seis horas após a lesão e quando não há presença de edema excessivo ou processo infeccioso (Auer e Stick, 2012). Para a realização da terapia, o animal permaneceu internado na Cevet e o tratamento preconizado consistiu de administração de flunixin meglumine $(1,1 \mathrm{mg} / \mathrm{Kg}$, IV, cada 24 horas), com o intuito de controlar o processo inflamatório local, reduzindo a dor e o edema, e omeprazol $(2 \mathrm{mg} / \mathrm{kg}$, VO, cada 24 horas) durante cinco dias consecutivos, além de curativo local. A associação do omeprazol ao tratamento foi realizada para a prevenção de lesões gastrointestinais, que são normalmente relatadas quando há uso de anti-inflamatórios não esteroidais em equinos (Silva et al., 2002).

O manejo diário da lesão consistia em realização de ducha fria diretamente no prepúcio, seguida de massagem com dimetil sulfóxido (DMSO) gel; ao redor da lesão era aplicado spray repelente. 0 pênis era exposto para limpeza da ferida, a qual era realizada com gaze embebida em solução de $\mathrm{NaCl} 0,9 \%$, seguida pela aplicação de pomada à base de clorexidina $(0,7 \mathrm{~g} / 100 \mathrm{~mL})$, procedimento este realizado a cada 12 horas, durante 45 dias. Justificou-se este tratamento devido à presença do quadro infeccioso local, para o qual se recomenda o uso de pomada de ação antimicrobiana (bactericida ou bacteriostática), além do uso do flunixin meglumine, com o intuito de modular a inflamação e, consequentemente, reduzir o edema prepucial (Silva et al., 2002; Schumacher e Varner, 2011).

No caso relatado, o animal foi previamente medicado com anti-inflamatórios esteroidais (dexametasona), o que consiste em uma prática comum, porém contraindicada, uma vez que atrasa o processo cicatricial e, em casos de infecção presente, pode agravar a situação. Indica-se, portanto, o emprego de anti-inflamatórios não esteroidais, além de curativo diário da ferida com pomada antimicrobiana (Schumacher e Varner, 2011), como foi realizado após a entrada do animal na clínica escola.

No segundo dia de tratamento, observou-se a diminuição do edema, e a partir do quinto dia o animal já expunha o pênis para urinar (Figura 1B).
Ao completar dez dias de tratamento, observouse redução do tecido de granulação e aproximação das bordas da ferida (Figura 1C). A completa cicatrização ocorreu aos 45 dias de tratamento (Figura 1D), quando o animal recebeu alta hospitalar. A recuperação do animal foi satisfatória, já que na estação de monta seguinte, o animal retornou às atividades reprodutivas sem apresentar alterações anatomofisiológicas.

Em função de uma das causas de infertilidade em garanhões ser a ocorrência de traumas envolvendo o pênis e o prepúcio, o exame físico específico da genitália externa é de extrema importância para realizar o diagnóstico preciso e, dessa forma, estabelecer o tratamento correto o mais rápido possível (Borges et al., 2017). Dentre os traumas, as lacerações na genitália externa são consideradas uma condição de risco para os garanhões e devem ser tratadas como emergência, a fim de se evitar danos à habilidade de realização da cópula e, em especial, à ejaculação. As lesões traumáticas, em sua grande maioria, interrompem a estação de monta ou diminuem a eficiência reprodutiva do garanhão, justificando a importância econômica da enfermidade em questão (Silva et al., 2010).

Pode-se concluir que a avaliação da extensão da lesão é primordial para a escolha adequada do tratamento, e este deve ser empregado o mais rápido possível para que ocorra completa recuperação do animal, sem trazer prejuízo para sua atividade reprodutiva. Dessa maneira, a terapêutica empregada nesse relato mostrou-se eficiente, pois o animal obteve cura clínica e não apresentou sequelas decorrentes da enfermidade, podendo ser utilizada em casos semelhantes ao descrito.

\section{Referências}

Auer JA, Stick JA. Equine Surgery. 4 ed. Philadelphia: Saunders; 2012.

Borges NC, Noronha-Filho ADF, Araujo GHM, MoyaAraujo CF. Semiologia do aparelho reprodutor do macho bovino e equino. In: Rabello RE, Silva LAF, Silva OC, Vulcani VAS. Cirurgias do aparelho reprodutor de machos bovinos e equinos. São Paulo: MedVet; 2017. p. 79-93. 
Franco LG, Villela ACV, Santos GP. Contenção química e anestesia da genitália externa do macho equino. In: Rabello RE, Silva LAF, Silva OC, Vulcani VAS (Org.). Cirurgias do aparelho reprodutor de machos bovinos e equinos. São Paulo: MedVet; 2017. p. 67-78.

Perkins JD, Schumacher J, Waguespack RW, Hanrath M. Penile retroversion and partial phallectomy performed in a standing horse. Vet Rec. 2003;153(6):184-5.

Schumacher J, Varner DD. Abnormalities of the penis and prepuce. In: McKinnon AO, Squires EL, Vaala WE, Varner DD (EE.). Equine Reproduction. 2 ed. Iowa: WileyBlackwell; 2011. p. 1130-44.
Silva IC, Alvarenga J, Klemm M. Efeitos de drogas antiinflamatórias não esteroidais e estresse sobre a mucosa gástrica de equinos. Rev Bras Cienc Vet. 2002;9(1):92-4.

Silva LAF, Rabelo RE, Godoy RF, Silva OC, Franco LG, Coelho CMM, et al. Estudo retrospectivo de fimose traumática em equinos e tratamento utilizando a técnica de circuncisão com encurtamento de pênis (19822007). Cienc Rural. 2010;40(1):123-9.

Taylor NR. Traumatic balanoposthitis in a yearling Appaloosa colt. Vet Rec. 1980;107(7):154-5. 